\title{
Kinematic quantification of straight-punch techniques using the preferred and non-preferred fist in taekwon-do
}

\author{
Jacek Wąsik ${ }^{1}$, Tomasz Góra ${ }^{1}$, Dorota Ortenburger ${ }^{1}$, Gongbing Shan ${ }^{2}$ \\ 1 Institute of Physical Education, Tourism and Physiotherapy, Jan Długosz University of Częstochowa, Częstochowa, \\ Poland; ${ }^{2}$ Department of Kinesiology, University of Lethbridge, Canada
}

\section{Summary}

Study aim: The aim of the current study is to reveal the characteristics of punch techniques applied in taekwon-do.

Material and methods: The skill quantification was performed on 10 taekwon-do ITF competitors. During the test, they were asked to perform straight punches using both the preferred and the non-preferred fist into the air (i.e. without a physical target) in the lateral position employing both traditional and sport style. Applying reflective markers on fists, the punching kinematic data were collected in the HML (Human Motion Lab). For data analyses, the average and standard deviation of duration, velocity and acceleration were used. The Mann-Whitney U test was applied to determine possible differences $(p<0.05)$ between the dominant fist and non-dominant fist as well as between the traditional and sport punch.

Results: The results revealed that the sport punch is notably faster (shorter punch duration) with a higher acceleration than the traditional one. There is no significant difference between the preferred and non-preferred fist. The results could suggest that the left and right straight punches during taekwon-do training sessions are equally developed. However, the different goals of the punch techniques, i.e. the traditional punch for generating power and the sport punch for quickness, cause significant differences $(\mathrm{p}<0.01)$ in action time.

Conclusion: The results imply that a trade-off strategy may play a role in a match, namely a powerful punch for a possible final win or a quick punch for point collection.

Key words: Martial arts biomechanics - Traditional style punch - Sport style punch - Decisionmaking

\section{Introduction}

The straight punch is a relevant training element of traditional taekwon-do (International Taekwon-do Federation). In a competition, it is often applied for attacks and counter-attacks [4]. Especially, in close matches, it plays a decision role for point collection, which is vital for winning a match [28]. This is why the proper acquisition of the straight punch and the use of the technique belong to the fundamentals of traditional taekwon-do, whereas the Olympic version of taekwondo (World Taekwondo Federation) is dominated by various kicking techniques [7, 32].

For decades, many different researchers have already undertaken investigations to identify biomechanical factors that have an impact on the efficiency of the punches. They studied the kinematic aspects of straight punches by using $2 \mathrm{D}$ motion analysis on punches with bare fists
$[3,23,24]$. Due to the simplicity of the early studies, the characteristics of some factors influencing punch quality remained unknown. Since then, scientific exploration in this area has been continuing for searching more details related to punch quality $[5,29,30]$. Pieter and colleagues have identified differences in velocities and strength between straight punches and kicks - both lateral and round. Furthermore, they compared straight punches from two different initial positions [14]. Their results suggested that more accurate quantitative research (e.g. 3D quantification) is needed for a better understanding of these techniques. Another research team has confirmed the same concern [24]. However, some studies have revealed certain aspects; e.g. the study done by Wąsik et al. [31] demonstrated that the moment for obtaining maximum velocity of a fist is influenced by the distance to the target.

The present study is a further exploration of straight punches aiming at quantification of the relationship among 
duration/time, velocity and acceleration in two different performing techniques. Based on the criteria of biomechanical analysis of sport techniques [8], especially the measurement of the techniques used in taekwon-do [29, 30], the following research questions have been asked:

1. How do the different punch techniques influence the punch kinematics?

2. What is (are) the biomechanical potential(s) of various punching techniques?

3. Are there kinematic differences between punches using the preferred and non-preferred fist?

The answers to these questions could build a solid foundation upon which the biomechanical identification of factors influencing punch effectiveness could be accurately performed.

\section{Material and methods}

\section{Participants}

The analysis was performed on 10 taekwon-do ITF (International Taekwon-do Federation) competitors (age: $21.2 \pm 6.2$ years; body height: $175.9 \pm 10.1 \mathrm{~cm}$; body weight: $69.5 \pm 13.5 \mathrm{~kg}$ ). On average, our subjects have 2.33 hours/week training for the traditional version of the straight punch and 2.5 hours/week for the sport version of the straight punch.

According to the literature in the field of cognitive-behavioural psychology, preference is one's habit, resulting from a long-term practice for a given person to choose one of the options available when performing specific tasks [6]. As such, an estimation of the preference in the selection of the left or right limb to perform a powerful punch was done for each subject.

This study was approved by the Bioethics Committee in Rzeszow, approval no. 2/6/2017, and was performed in accordance with the international ethical standards.

\section{Procedures}

During the test, the subjects performed two different styles (i.e. traditional technique and sport technique) of straight punch into the air, in a lateral position without a physical target (Fig. 1). For each style, the subjects performed six punches: three with the dominant fist and three with the non-dominant fist. In total, data of 120 trials were collected. The beginning of the fist movement was identified as the moment of the last value of $0 \mathrm{~m} / \mathrm{s}$ of speed in the initial phase, while the end of the movement was defined as the moment when the speed returned to $0 \mathrm{~m} / \mathrm{s}$ during the braking phase.

\section{Data Collection}

The research was accomplished in the Human Motion Lab (HML). A 10-camera VICON MX-T40 motion capture system (VICON Motion Systems, Oxford Metrics Ltd., Oxford, England, www.vicon.com) was set up to track fist markers (heads of 3rd metacarpals) at a rate of 370 frames/s. Calibration residuals were determined in accordance with VICON's guidelines and yielded positional data accurate within $1 \mathrm{~mm}$.

\section{Data Processing}

The 3D data were first filtered using a 5-point filter (a filter function in VICON software). Then, based on the filtered 3D data, the dynamic punch velocity and punch acceleration (i.e. their excursions over time) were calculated using MS Excel 2010. Also, the quantifications of peak values of velocity and acceleration were performed in Excel 2010. These values were applied in the statistical analysis. The punch duration was determined by two moments: at the last value of $0 \mathrm{~m} / \mathrm{s}$ of velocity in the initial phase and when the velocity returned to $0 \mathrm{~m} / \mathrm{s}$ during the braking phase.

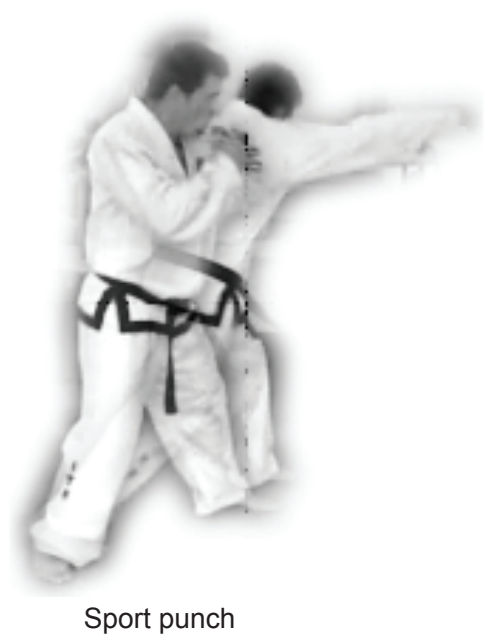

Fig. 1. Postural differences related to the two versions of the punch studied 
Table 1. Kinematic characteristics of straight punches tested. The statistical significance level was set at $\mathrm{p}<0.05$

\begin{tabular}{|c|c|c|c|c|}
\hline & \multirow{2}{*}{ Parameters } & \multicolumn{2}{|c|}{ Punching techniques } & \multirow{2}{*}{$\mathrm{p}$} \\
\hline & & Sport punch & Traditional punch & \\
\hline \multirow{3}{*}{ Preferred fist } & Punch duration [s] & $0.49 \pm 0.17$ & $0.87 \pm 0.32$ & 0.00 \\
\hline & Max velocity $[\mathrm{m} / \mathrm{s}]$ & $9.37 \pm 1.93$ & $9.17 \pm 3.04$ & 0.22 \\
\hline & Max acceleration $\left[\mathrm{m} / \mathrm{s}^{2}\right]$ & $236.40 \pm 279.40$ & $133.30 \pm 116.30$ & 0.04 \\
\hline \multirow{3}{*}{ Non-preferred fist } & Punch duration $[\mathrm{s}]$ & $0.46 \pm 0.13$ & $0.84 \pm 0.29$ & 0.00 \\
\hline & Max velocity $[\mathrm{m} / \mathrm{s}]$ & $9.01 \pm 2.29$ & $8.79 \pm 3.68$ & 0.13 \\
\hline & Max acceleration $\left[\mathrm{m} / \mathrm{s}^{2}\right]$ & $189.00 \pm 170.20$ & $146.10 \pm 151.10$ & 0.02 \\
\hline
\end{tabular}

\section{Statistical Analysis}

The data analyses focused on the characterization of punch duration, velocity and acceleration. Therefore, the average and standard deviation of the selected parameters were calculated. The Shapiro-Wilk test was carried out; it did not confirm the normality of the distribution. Therefore, the Mann-Whitney $U$ test was applied to identify any significant difference between punch techniques and between the dominant and non-dominant fist. The significance level was set at $p<0.05$. Statistical software SPSS V20 was applied for all data analyses.

\section{Results}

Three-dimensional motion analysis of selected parameters revealed distinguishable kinematic characteristics (mean $\pm \mathrm{SD}$ ) and significant differences between punch techniques and between the preferred and nonpreferred fist (Table 1). Comparing the sport punch to the traditional punch, a highly significant difference $(\mathrm{p}<0.00)$ was observed in punch duration and a significant difference $(p<0.05)$ in punch acceleration for both the preferred and the non-preferred fist (Table 1). The duration of the sport punch $(0.49 \pm 0.17 \mathrm{~s}$ and $0.46 \pm 0.13 \mathrm{~s}$ for the preferred and non-preferred fist respectively) was over $70 \%$ faster than that of the traditional punch $(0.87 \pm 0.32 \mathrm{~s}$ and $0.84 \pm 0.29 \mathrm{~s}$ for the preferred and non-preferred fist respectively). Regarding the maximum acceleration, the sport punch $\left(236.40 \pm 279.40 \mathrm{~m} / \mathrm{s}^{2}\right.$ and $189.00 \pm 170.30 \mathrm{~m} / \mathrm{s}^{2}$ for the preferred and non-preferred fist respectively) was over $70 \%$ and $30 \%$ higher than that of the traditional punch using the preferred fist (133.30 \pm 116.30$)$ and nonpreferred fist $(146.10 \pm 151.10)$ respectively. No significant difference was found for punch velocity. Figure 2 shows a typical punch velocity change over time for the two punch techniques in taekwon-do. Additionally, no significant differences were found for the three selected parameters when comparing punches using the preferred fist to those using the non-preferred fist $(\mathrm{p}>0.05)$.

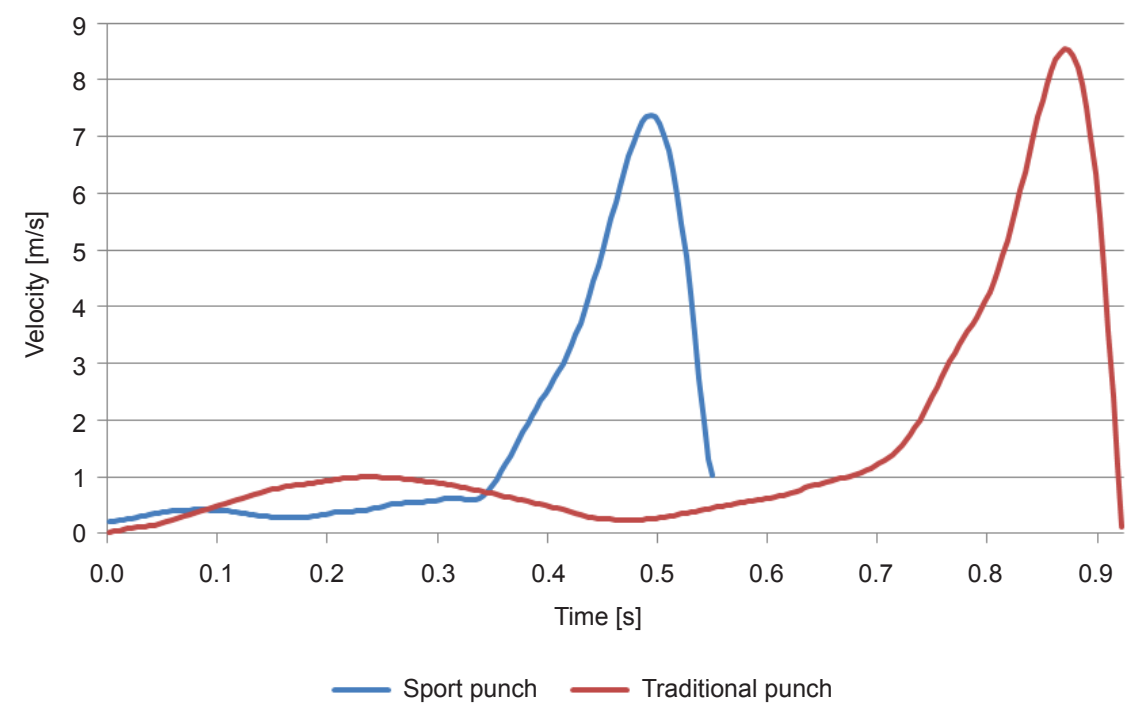

Fig. 2. An exemplary chart showing the fist velocity changes using different punch techniques: sport/boxing type (blue line), traditional type (red line) 


\section{Discussion}

Previous studies have shown that there is often a gap between biomechanical research and coaching/training practice; and coach-friendly research papers are highly desired by practitioners $[22,28,33]$. The current study aims to bridge the gap for taekwon-do training. By selecting relevant and easily understandable variables for coaches, practitioners and athletes, this study provides practitioners the following information: 1) kinematic characteristics of the punching fist, 2) kinematic differences between punch techniques and between the preferred and non-preferred fist, and 3) principal parameters that contribute to the punch quality. A better understanding of these characteristics would help practitioners better develop goal-oriented training programmes for improving training effectiveness.

In taekwon-do, straight punches are mainly applied for winning points - central to any close match. One effective way of winning points is to punch as fast as possible when "an opening" is identified during a match. Empirical evidence indicates that three parameters in particular can be used to evaluate the effectiveness (quality) of a straight punch: 1) the punch duration, 2) the maximum punch speed, and 3) the maximum punch acceleration. The shorter the punch duration is, the higher is the punch velocity, and the greater the punch acceleration is, the more likely it is to win points.

The results of the current study suggest that the effectiveness of a straight punch is indeed influenced by punch duration and acceleration, but may not be influenced by the punch velocity. It is interesting to see that the fist acceleration is higher when the time of movement is shorter in the sportive punch than that in the traditional punch. This could be du to a higher deceleration when the elbow is close to the full extension for avoiding elbow hyperextension as well as for avoiding an invalid high impact. Further studies on arm kinematics are needed to verify the mechanism. The traditional punch $(0.87 \mathrm{~s})$ is notably slower than the sport punch $(0.49 \mathrm{~s})$. The shorter action time of the sport punch may be due to the technique's potential for generating higher acceleration than a traditional punch.

Regarding the use of the preferred and non-preferred fist, the results imply equal development of both the left and right fist. Such development could be rooted in the long-standing tradition/training strategy of taekwon-do practice, i.e. equal/symmetric physical training for both upper limbs. The strategy would result in a long-term benefit: as the increase of flexibility is obtained through training, equal attacks from both arms would win more chances for collecting points. From the neural-biological point of view, the training of a non-preferred limb would positively cause an adaptation of brain structure that goes along the frontal lobe in its deeper parts [1]. This adaptation is referred to as the frontal part of the brain cingulum, or its "gearbox". Depending on the environmental requirements, the adaptation may cause an alteration of motor behaviour, allowing a correction of one's motor control [2]. In psychology, such a type of characteristics is referred to as cognitive flexibility [25], which has a beneficial impact on both competitions and daily life.

In sports practice, trade-offs (e.g. between accuracy and power, between balancing and power) have to be made depending on the goals selected [13, 20, 21]. A similar situation happens to the punch techniques. The two analysed types of punch (sport vs traditional) reflect two types of use. The sport punch technique in taekwon-do aims to win points, whereas the traditional punch technique is applied to generate power ( $=$ force $\times$ velocity), e.g. to break boards. For the sport punch, in order to increase effectiveness, the time of performance must be shortened, as the aim is not the opponent's knockout but the result of "touching" and winning the point (i.e. trade-off of power for quickness). For the traditional, power-generation punch (i.e. producing maximum power at the moment of punching at the target), there is no time limitation. The different purposes of the two techniques should account for the notable variation in the punch duration.

One relevant research question related to straight punch is how does the selection of punch techniques work in competitions? The results of the current study and other empirical research $[9,11]$ seem to suggest that interactions among influencing factors would constitute the grounds for a change within the "brain gearbox". In a situation when the activity of the frontal part of the cingulate cortex is too intense, people reveal a higher tendency to block themselves when ineffective behaviours take place [1]. In many full contact self-defence situations or fights, one could often come across a mixture of decision making $[15,17]$ : a powerful punch for a possible final win or a quick punch for point collection. The dilemma would be whether to apply a traditional punch (powerful punch) with the risk of possibly losing body control (high risk, high award) [10] or perform a sport punch for an endurance match. In such a situation, the development of maximum power at the cost of time may mean the difference between "life" and "death". The results of the current study would supply preliminary insight for science-based decision making. More complicated and multi-disciplinary studies are needed for a holistic understanding of the factors related to application of punch techniques.

Finally, regarding lateralization, recent studies $[6,13$, $16,18]$ on various sports have revealed that taekwon-do shares the same mechanism with other sports. The phenomenon of lateralization manifests itself in the appearance of certain preferences, which results from a long-term practice for a given person to choose one of the options 
available when performing specific tasks [6]. The results suggest that training plays a role in lateralization. A similar example of lateralization is the preferred and non-preferred leg in soccer players [16, 19]. Additionally, further studies indicate that laterality in sport does not have a clear impact on sports results because training interventions can reduce the effects of lateralisation on sporting performance and improve performance [13]. Our study provides arguments confirming this point (Table 1).

\section{Conclusion}

The results of the current study confirm that the preferred and non-preferred fist straight punches during taekwon-do training are equally developed. However, the different goals of the punch techniques, i.e. the traditional punch for generating power and the sport punch for quickness, cause kinematic differences between the two punch techniques. Hence, the applications of the two techniques should be different. These results imply that a trade-off strategy should play a role in a match, namely a powerful punch for a possible final win or a quick punch for point collection. In short, the current study provides a preliminary insight into science-based decision making during competitions for practitioners.

\section{Conflict of interest: Authors state no conflict of interest.}

\section{References}

1. Amen D. (2006) Making a good brain great: The Amen clinic program for achieving and sustaining optimal mental performance. New York: Harmony.

2. Amen D. (2010). Change your brain, Change your body: Use your brain to get and keep the body you have always wanted. London: Harmony.

3. Blum H. (1977) Physics and the art of kicking and punching. Am. J. Phys., 45(1): 61-64.

4. Bujak Z. (2004) Wybrane aspekty treningu w taekwondo [in Polish]. Warszawa: ZWWF Biała Podlaska.

5. Chang S.T., Evans J., Crowe S., Zhang X., Shan G. (2011) An innovative approach for real time determination of power and reaction time in a martial arts quasitraining environment using 3D motion capture and EMG measurements. Arch. Budo., 7(3): 185-196.

6. Colman A. (2015) Dictionary of Psychology. Oxford University Press. ISBN: 9780199657681.

7. Cular D., Munivrana, G., \& Katic, R. (2013). Anthropological analysis of taekwondo - New methodological approach. Collegium Antropologicum, 37(2): 9-18.

8. Hay J. (1993) The biomechanics of sport techniques. Englewood Cliffs, NJ: Prentice-Hall.
9. Hylchuk Y., Andreichuk O., Pantik V., Tsymbaliuk S. (2017) Physical and mental health components condition in the life quality of students who regularly practice kickboxing and yoga. Phys. Activ. Rev., 5: 37-43. DOI: 10.16926/par.2017.05.06.

10. Kalina R.M. (2000) Teoria sportów walki [in Polish]. Warszawa: Centralny Ośrodek Sportu.

11. Leite W.S.S. (2014) Competition versus nature: how the sport warps human character. Phys. Activ. Rev., 2: 1-9.

12. Li S., Zhang Z., Wan B., Wilde B., Shan G. (2017) The relevance of body positioning and its training effect on badminton smash. J. Sports Sci., 35(4): 310-316.

13. Maloney S.J. (2018) The relationship between asymmetry and athletic performance: a critical review. J. Strength Cond. Res., DOI: 101519/JSC. 0000000000002608.

14. Pieter F., Pieter W., Heijmans J. (1987) Movement analysis of taekwondo techniques. Asia J. Phys. Educ, 10(3): 45-58.

15. Pobratyn A., Ciesielska Z., Lesiak K., Ziental A. (2017) Eastern Martial Arts in cinematography and popularising a healthy lifestyle-interpretation sketch. Phys. Activ. Rev., 5: 78-82. DOI: 10.16926/par.2017.05.11.

16. Rahnama N., Lees A., Bambaecichi E. (2005) A comparison of muscle strength and flexibility between the preferred and non-preferred leg in English soccer players. Ergonomies, 48(11-14): 1568-1575.

17. Romanenko V., Podrigalo L., Iermakov S., Rovnaya O., Tolstoplet E., Tropin Y., Goloha V. (2018) Functional state of martial arts athletes during implementation process of controlled activity-comparative analysis. Phys. Activ. Rev., 6: 87-93. DOI: 10.16926/par.2018.06.12.

18. Sachlikidis A., Salter C. (2007) A biomechanical comparison of dominant and non-dominant arm throws for speed and accuracy. Sports Biomech., 6, 3: 334-345.

19. Shan G., Daniels D., Wang C., Wutzke C., Lemire G. (2005) Biomechanical analysis of maximal instep kick by female soccer players. J. Hum. Mov. Stud., 49: 149-168.

20. Shan G., Visentin P., Zhang X., Hao W., Yu D. (2015) Bicycle kick in soccer: is the virtuosity systematically entrainable? Science Bulletin, 60(8): 819-821.

21. Shan G., Westerhoff P. (2005) Full body kinematic characteristics of the maximal instep Soccer kick by male soccer players and parameters related to kick quality. Sports Biomechanics, 4(1): 59-72.

22. Shan G., Zhang X., Wan B., Yu D., Wilde B., Visentin P. (2018) Biomechanics of coaching maximal instep soccer kick for practitioners. Interdisciplinary Science Reviews, 44(1): 12-20, DOI: 10.1080/03080188.2018.1534359.

23. Stull R., Barham J. (1988) An analysis of movement patterns utilized by different styles in the karate reverse punch in front stance. Paper presented at the ISBS-Conference Proceedings Archive.

24. Vos J., Binkhorst R. (1966) Velocity and force of some karate arm-movements. Nature, 211(5044): 89. 
25. Wade C., Tavris C. (1998) Psychology (5th ed.). New York: Longman.

26. Walker J.D. (1975) Karate strikes. Am. J. Phys., 43(10): 845-849.

27. Wang Y., Li H., Wan B., Zhang X., Shan G. (2018) Obtaining Vital Distances Using Wearable Inertial Measurement Unit for Real-Time, Biomechanical Feedback Training in Hammer-Throw. Appl. Sci., 8(12): 2470. DOI: $10.3390 /$ app8122470.

28. Wassik, J., Pieter, W., Borysiuk, Z. (2014). The effect of offensive and defensive actions on taekwondo sparring. Journal Combat Sports and Martial Arts, 5(1): 27-30. DOI: $10.5604 / 20815735.1127450$

29. Wassik, J., Shan, G. (2014). Factors influencing the effectiveness of axe kick in taekwon-do. Arch Budo., 10(1): 29-36

30. Wassik J. (2015) Kinetics of the knife-hand strike used in power breaking in ITF Taekwon-do. Phys. Activ. Rev., 3: 37-43. DOI: 10.16926/par.2015.01.05.
31. Wąsik J., Ortenburger D., Gora T., Mosler D. (2018) The influence of effective distance on the impact of a punchPreliminary Analysis. Phys. Activ. Rev., 6: 81-86. DOI: 10.16926/par.2018.06.11.

32. Yu D., Yu Y., Wilde B., Shan, G. (2012) Biomechanical Characteristics of the Axe Kick in Tae Kwon-Do. Arch. Budo, 8(4): 213-218.

33. Zemkova E. (2018) Science and practice of core stability and strength testing. Phys Activ Rev., 6: 181-193. DOI: 10.16926/par.2018.06.23.

\section{Received 12.02.2019 \\ Accepted 05.08.2019}

(C) University of Physical Education, Warsaw, Poland 